\title{
Determination of the distribution of nerve conduction velocities in chain saw operators
}

\author{
S ARAKI, K YOKOYAMA, H AONO, K MURATA \\ From the Department of Public Health and Hygiene, Medical College of Oita, Hazama-machi, Oita 879-56, \\ Japan
}

ABSTRACT By measuring the distribution of conduction velocities (DCV) in sensory fibres of the median nerve, the effects of local vibration on all faster and slower large myelinated nerve fibres were examined in 10 male chain saw operators (three operators had frequent attacks of white finger; the attacks were only occasional in four and negative in three). All parameters of DCV, and conventional sensory nerve conduction velocity were significantly slowed in the chain saw operators. It is suggested that local vibration affects the faster and slower nerve fibres; parameters of the DCV are sensitive indicators of both the neurological and vascular effects.

Slowing of peripheral nerve conduction velocities in vibrating tool operators has been observed in many studies including two by our group..$^{1-13}$ Most of these data indicate that the slowing is pronounced and distal segments of sensory and motor nerve fibres in the arms tend to be predominantly affected by local vibration. ${ }^{1-6891112}$ The pronounced physiological changes are compatible with the pathological data of Takeuchi et $a l^{14}$ 15 who showed a demyelinating neuropathy in the finger of patients with vibration induced white finger.

We have recently established a transcutaneous technique to derive the distribution of conduction velocities (DCV) of several thousand large myelinated nerve fibres ( $\alpha$ fibre group) in peripheral nerve trunks. ${ }^{16}$ As the conventional methods for determining conduction velocities yield only two discrete values that reflect the maximal and slower velocities of fibres in the nerve trunk, determination of the DCV is essential for assessing conduction velocities of all large myelinated nerve fibres in parallel to the fibre diameters. In the present study the technique has been applied to chain saw operators to investigate the physiological effects of local vibration on all faster and slower nerve fibres.

\section{Subjects and methods}

\section{SUBJECTS}

Ten male forest workers, aged 41 to 59 (mean 53), were examined in March 1986. Their subjective symptoms and clinical stages (Taylor-Pelmear and USSR-Japan classifications $)^{17}$ are shown in table 1 . The workers had

Accepted 12 January 1987
Table 1 Subjective symptoms at work and clinical stages in ten chain saw operators

\begin{tabular}{ll} 
& No \\
\hline Symptoms: & 9 \\
Numbness in upper extremities & $7^{*}$ \\
White finger attack & 6 \\
Arthralgia & 5 \\
Diminished sense of touch in fingers & 5 \\
Pain in upper extremities & 4 \\
Distal muscle weakness & 4 \\
Sensory symptoms in legs & 4 \\
Insomnia & 4 \\
Low back pain & 3 \\
Neck pain & 3 \\
Tremor & 1 \\
Headache & 1 \\
Vertigo & 1 \\
Stages (Taylor-Pelmear classification): + & 1 \\
0 & 1 \\
$0_{N}$ & 2 \\
$0_{\mathrm{TN}}$ & 5 \\
$2^{2}$ & \\
\hline
\end{tabular}

*Frequent attacks (stage III) in three; occasional attacks (stage II) in four (USSR-Japan classification).

+0 , Neither blanching of fingers nor complaints of tingling or numbness; $0_{\mathrm{N}}$, intermittent numbness of fingers but no blanching: $0_{\mathrm{TN}}$, intermittent tingling and numbness but no blanching; 1 , one or more finger tip blanching with or without tingling or numbness, or both, first noted in winter; 2 , blanching with extension beyond tips of one or more digits with or without tingling and numbness complained of in winter months.

engaged in chain saw operations for 16 to 26 (mean 22) years; in 1985 they worked for 50-203 (mean 122) days (average working hours a day were $3 \cdot 5$, range $0 \cdot 5-6 \cdot 0$ ). All workers drank alcohol equivalent to 95-755 (mean $401) \mathrm{ml}$ of $100 \%$ ethanol a week and smoked $0-30$ (mean 13) cigarettes a day. None was occupationally exposed to neurotoxic substances such as heavy metals 
and solvents and none had ever suffered from neurological disease, diabetes mellitus, or renal disease.

Control subjects, matched to each chain saw operator by sex and age (male sex and same five year span), were selected randomly from 25 male "healthy" workers living in the same residential area as the chain saw operators. They neither engaged in occupations using vibrating tools nor suffered from neurological, endocrinological, or renal disease. Their age, alcohol ingestion, tobacco consumption, and skin temperature at the time of electrophysiological study did not differ significantly from those of the chain saw operators (paired sample $t$ test, $t=-2.02,-1.80$, 0.04 , and -1.34 respectively, $p>0.05$ ).

\section{METHODS}

Electrophysiological studies were conducted in a warm laboratory $\left(28-32^{\circ} \mathrm{C}\right)$ using a Medelec MS-92 two channel electromyograph; skin temperature was maintained in the range of $30-34^{\circ} \mathrm{C}$ for all subjects. The DCV was measured by the same method reported previously by us (a modified method of Barker et al). ${ }^{16}{ }^{18}$ After electrical stimulation of the right median nerve at the second finger with a 70 to $100 \mathrm{~V}$ square wave pulse of $0.2 \mathrm{msec}$ duration, the compound action potential (CAP) was picked up at the wrist and the elbow. Typical records of the CAP are illustrated in fig 1 with the calculated single fibre action potential. The DCV was calculated between the velocities of 30.0 and $77.5 \mathrm{~m} / \mathrm{sec}$ by the double conduction distance method $^{18}$ using a Hitachi MB6891 microcomputer. The calculated DCV was expressed by the following parameters: the conduction velocities below which 10 , $20,30,40,50,60,70,80$, and $90 \%$ of active nerve fibres lie (V10, V20, V30, V40, V50, V60, V70, V80, and V90 velocities); arithmetic mean of the conduction velocities (Vmean); and mode of the conduction velocities (Vpeak).

The maximal sensory nerve conduction velocity of the right median nerve (SCV) was calculated from the two CAPs for the areas from the finger to the wrist and the elbow and from the wrist to the elbow. ${ }^{19}$ Daily variations in the DCV and SCV (coefficients of variation) have been described previously. ${ }^{16}$

\section{Results}

The DCVs in 10 chain saw operators and in 10 matched controls are illustrated in fig 2 . All parameters of DCVs and SCVs were significantly slowed in the chain saw operators (table 2). Figure 3 exemplifies the differences in DCVs and SCVs between chain saw operators and the controls. The SCV from the wrist to the elbow was significantly correlated with total working days in 1985 in the chain saw operators $(r=-0.66, p<0.05)$. (a)

CAPs at wrist (above) and elbow (below)
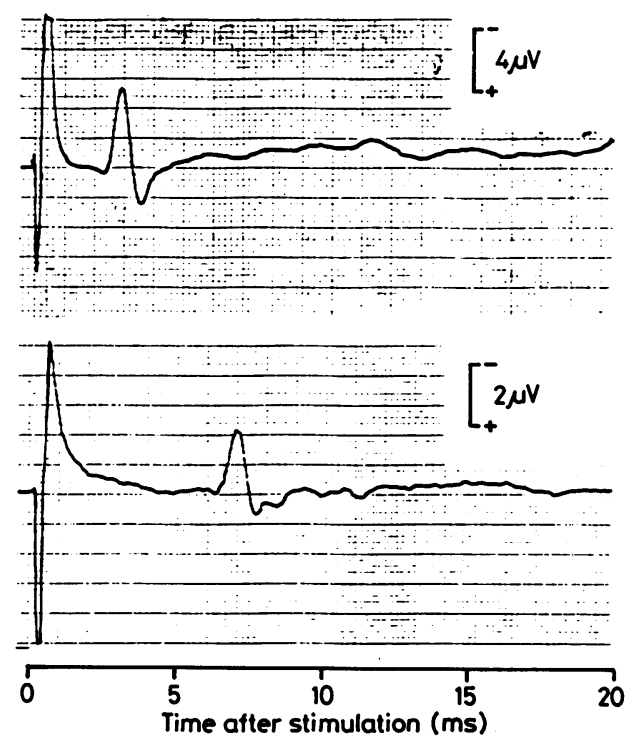

(b)

SFAP calculated

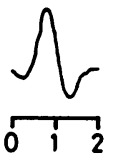

Time after stimulation (ms)

Fig 1 Compound action potentials (CAPs) recorded from median nerve at wrist and elbow after stimulation of second finger in a chain saw operator and calculated single fibre action potential (SFAP, relative amplitude) corresponding to conduction velocity of $60.0 \mathrm{~m} / \mathrm{sec}$.

\section{Discussion}

According to a previous study the only parameter of DCV which was significantly slowed in workers exposed to lead, zinc, and copper was the V10 velocity. ${ }^{16}$ In a patient with acute thalium poisoning only the V70-V90 velocities were significantly slowed whereas in 10 patients suffering from diabetes mellitus the V30-V90 velocities were slowed. ${ }^{20}$ By contrast, in the present group of chain saw operators, all parameters were significantly slowed. Thus the effects of local vibration on peripheral nerve conduction velocities appear to be more extensive than those of many other causes.

In 29 pneumatic vibrating tool operators with frequent or very frequent attacks of white finger (stage III or IV in USSR-Japan classification), Takeuchi et al 


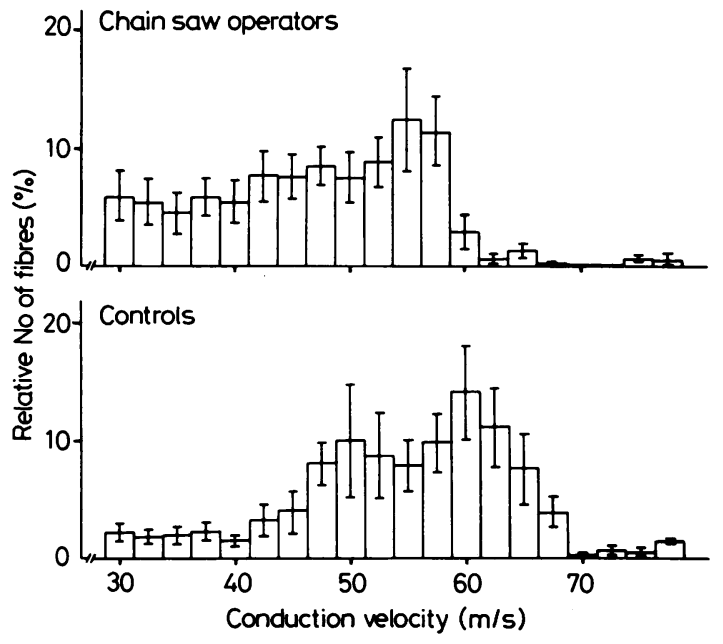

Fig 2 Distribution of conduction velocities in 10 chain saw operators and same number of matched controls (averages and standard errors).

observed a demyelinating neuropathy with a pronounced loss of nerve fibres. ${ }^{14}{ }^{15}$ In the present study, on the other hand, seven of the ten chain saw operators had only occasional or negative attacks of white finger (stage I or II) (table 1). Therefore, pathological changes in the peripheral nerves of the present group of workers, if any, might have been less prominent.

Figure 3 suggests that chain saw operators with white finger attacks tend to have slower conduction velocities for all parameters of DCV than those without. The parameters of DCV, therefore, may be sensitive indicators of the vascular effects of local vibration as well as the neurological effects. Studies are needed to clarify whether or not vasomotor nerve fibres are similarly affected by local vibration and whether changes in the DCV are the direct effects of vibration or result from white finger attacks.

The close relation between changes in the DCV and attacks of white finger in the present study, however, contrasts with the observations in two previous studies $^{413}$ which indicated that slowing of SCV is independent of white finger attacks. The latter observation is also confirmed in the present study (fig 3 ). We have no convincing explanation to offer for this apparent discrepancy.

Finally, in the present study none of the parameters of DCV was significantly correlated with either total working years or total working days in 1985 (p > 0.05 ). On the other hand, the SCV in the forearm segment was significantly correlated with total working days in 1985. Similarly, Ho and Yu have reported significant correlations between conventional motor and sensory nerve conduction velocities and total

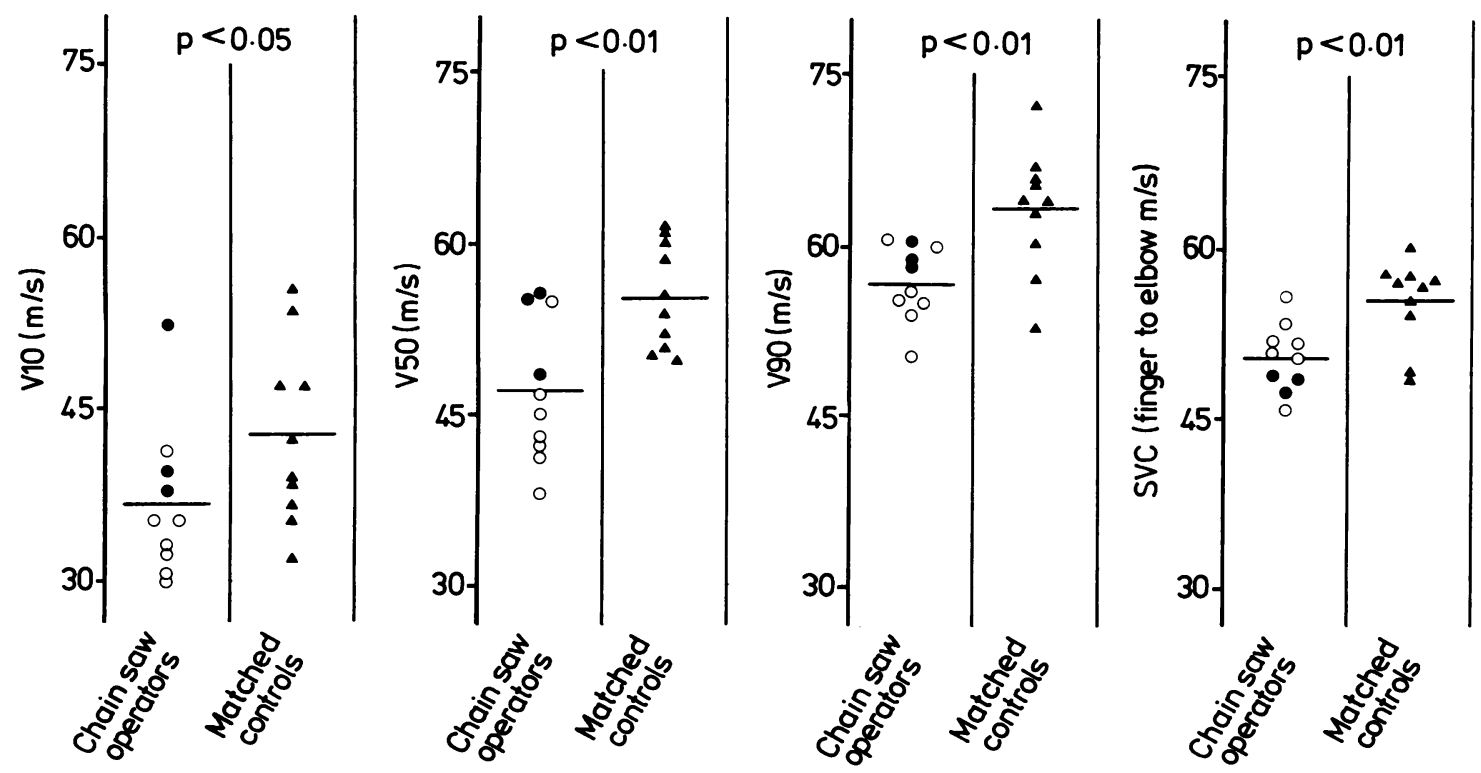

Fig 3 Differences in distribution of conduction velocities (V10,V50, and V90 velocities) and sensory nerve conduction velocity ( $S C V$ ) between 10 chain saw operators and same number of matched controls (paired sample $t$ test). Open ( $O$ ) and solid (-) circles indicate chain saw operators with and without a history of white finger attacks, respectively; black triangles ( $\Delta$ ) are matched controls. Transverse line shows mean values. 
Table 2 Differences in distribution of conduction velocities (V10-V90, Vmean, and Vpeak) and sensory nerve conduction velocity ( $S C V$ ) between 10 chain saw operators and the same number of matched controls (paired sample $t$ test)

\begin{tabular}{|c|c|c|c|}
\hline Conduction velocities $(\mathrm{m} / \mathrm{sec})$ & Chain saw operators* & Matched controls* & Matched differences $\dagger$ \\
\hline $\begin{array}{l}\text { V10 } \\
\text { V20 } \\
\text { V30 } \\
\text { V40 } \\
\text { V50 } \\
\text { V60 } \\
\text { V70 } \\
\text { V80 } \\
\text { V90 } \\
\text { Vmean } \\
\text { Vpeak } \\
\text { SCV (finger to wrist) } \\
\text { SCV (wrist to elbow) }\end{array}$ & $\begin{array}{l}36 \cdot 7(30 \cdot 0-52 \cdot 3) \\
40 \cdot 4(31 \cdot 2-53 \cdot 3) \\
43 \cdot 4(34 \cdot 0-54 \cdot 1) \\
45 \cdot 3(35 \cdot 5-54 \cdot 6) \\
47 \cdot 0(38 \cdot 0-55 \cdot 4) \\
49 \cdot 3(42 \cdot 1-56 \cdot 3) \\
51 \cdot 5(45 \cdot 3-57 \cdot 4) \\
54 \cdot 1(48 \cdot 7-58 \cdot 5) \\
56 \cdot 7(50 \cdot 2-60 \cdot 5) \\
47 \cdot 3(40 \cdot 5-55 \cdot 2) \\
43 \cdot 5(30 \cdot 0-55 \cdot 0) \\
43 \cdot 1(37 \cdot 2-47 \cdot 5) \\
55 \cdot 8(51 \cdot 5-61 \cdot 7)\end{array}$ & $\begin{array}{l}42 \cdot 7(32 \cdot 0-55 \cdot 4) \\
47 \cdot 7(35 \cdot 5-58 \cdot 8) \\
51 \cdot 4(43 \cdot 6-59 \cdot 5) \\
53 \cdot 8(48 \cdot 1-60 \cdot 2) \\
55 \cdot 3(49 \cdot 8-61 \cdot 3) \\
57 \cdot 4(50 \cdot 8-64 \cdot 0) \\
58 \cdot 8(51 \cdot 2-64 \cdot 8) \\
61 \cdot 1(52 \cdot 1-66 \cdot 3) \\
63 \cdot 2(52 \cdot 9-72 \cdot 5) \\
54 \cdot 2(49 \cdot 2-60 \cdot 9) \\
56 \cdot 8(47 \cdot 5-62 \cdot 5) \\
49 \cdot 7(41 \cdot 2-62 \cdot 9) \\
59 \cdot 9(50 \cdot 9-63 \cdot 8)\end{array}$ & $\begin{array}{l}-6.0 \pm 8.2 \ddagger \\
-7.3 \pm 7.6 \ddagger \\
-8.0 \pm 8.1 \ddagger \\
-8.5 \pm 8.1 \S \\
-8.3 \pm 7.7 \S \\
-8.1 \pm 7.1 \S \\
-7.3 \pm 6.4 \S \\
-7.1 \pm 6.1 \S \\
-6.5 \pm 5.9 \S \\
-7.0 \pm 6.1 \S \\
-13.3 \pm 11.2 \S \\
-6.6 \pm 5.9 \S \\
-4.1 \pm 4.9 \ddagger\end{array}$ \\
\hline
\end{tabular}

* Mean with range in parentheses.

† Mean and standard deviation of matched differences.

$\ddagger \mathrm{p}<0.05 ;$ s $<0.01$.

operating time of vibration ${ }^{12}$; in a recent study we have also shown significant correlations between N9 and P23 latencies of short latency somatosensory evoked potentials (conduction times from the wrist to the neck and to the cerebral cortex) and total working days in the latest year. ${ }^{13}$ Studies with larger number of subjects are needed to investigate the relation between changes in DCV and duration of vibration work.

The present address of Drs Araki and Murata is: Department of Public Health, Faculty of Medicine, University of Tokyo, Hongo, Bunkyo-ku, Tokyo 113, Japan

\section{References}

1 Dylewska $D$. The study of conduction in the motor and sensory nerves of upper limbs in vibration disease. Neurol Neurochir Pol 1970;4:27-31. (In Polish.)

2 Seppäläinen AM. Peripheral neuropathy in forest workers: a field study. Work Environ Health 1972;9:106-11.

3 Nishi G, Kuno T, Sugiura Y, et al. Motor and sensory nerve conduction velocities in workers handling vibrating tools. Sangyo Eiken Nenpo 1972;4:1-5. (In Japanese.)

4 Araki S, Honma T, Aoyama K. Peripheral nerve conduction velocities in chain-saw operators. Japanese Journal of Industrial Health 1976;18:516-20.

5 Torii J, Kousaka K, Imanishi H. Peripheral neuropathy in chainsaw operators. Japanese Medical Journal 1978 No 2829:32-4. (In Japanese.)

6 Tanabe T, Kameda M. Somatosensory evoked potential and nerve conduction velocity in vibration disease. Clin Electroencephalogr 1979;21:324-8. (In Japanese.)

7 Chatterjee DS, Barwick DD, Petrie A. Exploratory electromyography in the study of vibration-induced white finger in rock drillers. Br J Ind Med 1982;39:89-97.

8 Hisanaga $H$. Studies of peripheral nerve conduction velocities in vibrating tool operators. Japanese Journal of Industrial Health 1982;24:284-93. (In Japanese.)
9 Juntunen J, Matikainen E, Seppäläinen AM, Laine A. Peripheral neuropathy and vibration syndrome: a clinical and neurophysiological study of 103 patients. Int Arch Occup Environ Health 1983;52:17-24.

10 Seppäläinen AM, Starck J, Harkonen H. High-frequency vibration and sensory nerves. Scand $J$ Work Environ Health 1986;12:420-2.

11 Sakurai T, Matoba T. Peripheral nerve responses to handarm vibration. Scand J Work Environ Health 1986;12:432-4.

12 Ho S-T, Yu H-S. A study of neurophysiological measurements and various function tests on workers occupationally exposed to vibration. Int Arch Occup Environ Health 1986;58:259-68.

13 Murata K, Araki S, Aono H. Assessment of central and peripheral nerve junction in chain-saw operators: a study of short-latency somatosensory evoked potential and peripheral nerve conduction. Tohoku J Exp Med 1987;151:25-31.

14 Takeuchi T, Imanishi H. Histopathologic observations in finger biopsy from thirty patients with Raynaud's phenomenon of occupational origin. Journal of the Kumamoto Medical Society 1984;58:56-70. (In Japanese.)

15 Takeuchi T, Futatsuka M, Imanishi H, Yamada S. Pathological changes observed in the finger biopsy of patients with vibrationinduced white finger. Scand $J$ Work Environ Health 1986;12:280-3

16 Araki S, Yokoyama K, Murata K, Aono H. Determination of the distribution of conduction velocities in workers exposed to lead, zinc, and copper. Br J Ind Med 1986;43:321-6.

17 Taylor $W$. Occupational disability arising from the vibration syndrome. In: Gemne G, Taylor W, eds. Hand-arm vibration and the central autonomic nervous system. London: Multi-Science Publishing Co, 1983:1-5.

18 Barker AT, Brown BH, Freeston IL. Determination of the distribution of conduction velocities in human nerve trunks. IEEE Trans Biomed Eng 1979;BME-26:76-81.

19 Araki S, Honma T. Relationships between lead absorption and peripheral nerve conduction velocities in lead workers. Scand $J$ Work Environ Health 1976;4:225-31.

20 Yokoyama K, Araki S, Murata K, Aono H. Distributions of nerve conduction velocities in vibrating tool operators, lead workers, diabetes mellitus and acute thalium poisoning. In: Proceedings of 16th meeting of Japan Society of Electroencephalography and Electromyography, Tsukuba, 1986. Japanese Journal of Electroencephalography and Electromyography 1987;15:167-8. (In Japanese.) 